\title{
Quantifying late-stage host-seeking behaviour of Anopheles gambiae at the insecticidal net interface using a baited-box bioassay
}

Angela Hughes ${ }^{1}$, Geraldine M. Foster ${ }^{1}$, Amy Guy ${ }^{1}$, Agnes Matope ${ }^{1}$, Mayumi Abe ${ }^{1}$, David Towers² and Philip J. McCall ${ }^{*}$

\begin{abstract}
Background: Insecticide-treated nets (ITNs) are losing efficacy against pyrethroid-resistant malaria vector populations throughout Africa. Safeguarding bed net efficacy, vital for effective malaria control, requires greater knowledge of mosquito-ITN interactions and how this impacts on the mosquito.

Methods: A purpose-built benchtop apparatus with a closed $10 \mathrm{~cm}$ cubic chamber (the 'Baited-box') was used to video record behaviour of individual free-flying female Anopheles gambiae during approach and blood-feeding on a human hand through untreated nets and ITNs at close range. Time and duration of defined behavioural events, and knockdown and mortality at 1- and 24-h post-exposure respectively, were recorded for pyrethroid susceptible and resistant mosquitoes.

Results: Using three human volunteers differing in relative attractiveness to mosquitoes, 328 mosquitoes were individually tested. There were no significant differences between response rates to ITNs and untreated nets $(P>0.1)$ or between resistant (Tiassalé) and susceptible (Kisumu) mosquito strains, at untreated nets $(P=0.39)$ or PermaNet $2.0(P=1)$. The sequence of behavioural events from host-seeking to completion of blood-feeding was consistent in all tests but duration and start time of events involving net contact were reduced or delayed respectively with ITNs. Blood-feeding durations at untreated nets (means from 4.25 to $8.47 \mathrm{~min}(95 \%$ confidence interval $(\mathrm{Cl})=3.39-9.89)$ at 3 human volunteers) were reduced by $37-50 \%$ at PermaNet 2.0, in susceptible (mean $2.59-4.72 \mathrm{~min}, 95 \% \mathrm{Cl}=1.54-$ $5.5, P=<0.05$ ) and resistant (mean $4.20 \mathrm{~min}, 95 \% \mathrm{Cl}=3.42-4.97, P=0.01$ ) strains. Total accumulated net contact was approximately $50 \%$ lower at PermaNet and Olyset ITNs $(P<0.0001)$ in susceptible (two of the three volunteers) and resistant mosquitoes. Times prior to first net contact were similar at untreated nets and ITNs $(P>0.2)$, and neither ITN type showed detectable spatial repellency. After initial contact, blood-feeding commenced later at Olyset (mean $2.76 \mathrm{~min}, 95 \% \mathrm{Cl}=1.74-3.76, P=0.0009$ ) and PermaNet (mean $2.4 \mathrm{~min}, 95 \% \mathrm{Cl}=1.52-3.33, P=0.0058$ ) than untreated netting (mean $0.68 \mathrm{~min}, 95 \% \mathrm{Cl}=0.42-0.94$ ).
\end{abstract}

Conclusions: The baited box offers a simple method for detailed characterization of mosquito behavioural responses to insecticidal nets, for comparing entomological modes of action between nets and for defining the behavioural

*Correspondence: philip.mccall@Istmed.ac.uk

${ }^{1}$ Department of Vector Biology, Liverpool School of Tropical Medicine, Pembroke Place, Liverpool L3 5QA, UK

Full list of author information is available at the end of the article

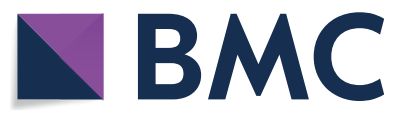

(c) The Author(s) 2020. This article is licensed under a Creative Commons Attribution 4.0 International License, which permits use, sharing, adaptation, distribution and reproduction in any medium or format, as long as you give appropriate credit to the original author(s) and the source, provide a link to the Creative Commons licence, and indicate if changes were made. The images or other third party material in this article are included in the article's Creative Commons licence, unless indicated otherwise in a credit line to the material. If material is not included in the article's Creative Commons licence and your intended use is not permitted by statutory regulation or exceeds the permitted use, you will need to obtain permission directly from the copyright holder. To view a copy of this licence, visit http://creativeco mmons.org/licenses/by/4.0/. The Creative Commons Public Domain Dedication waiver (http://creativecommons.org/publicdomain/ zero/1.0/) applies to the data made available in this article, unless otherwise stated in a credit line to the data. 
responses of particular mosquito strains or populations. The device has potential as a screening assay in the search for novel net treatments and for investigations into behavioural resistance mechanisms.

Keywords: Mosquito, Vector, Behaviour, Anopheles, ITN, Pyrethroid, Insecticide, Control, Bednet, ITN, Bioassay, Malaria

\section{Background}

Insecticide-treated nets (ITNs) are a highly effective method for preventing malaria in Africa [1]. They are fundamental to the Global Malaria Action Plan (GMAP) and its aims of universal coverage for sustainable malaria reduction and eventual elimination in affected communities [2]. ITNs deliver doses of pyrethroid insecticide (standard ITNs) or pyrethroid plus a second active ingredient (next generation bed nets) when the mosquito makes contact with the net surface. However, widespread insecticide resistance in Anopheles gambiae sensu lato (s.l.) and Anopheles funestus s.l., the two African malaria vector groups most effectively targeted by ITNs, is diminishing the effects of the insecticide dosage delivered such that standard ITNs have lost efficacy against resistant populations [3-8].

While the mechanisms of insecticide resistance in malaria vectors have been studied and characterized extensively at the molecular level, knowledge of behavioural changes associated with resistance is sparse, limited in part by the absence of suitable methods for exploring vector behaviour, as reiterated or clarified by many in the field [9-11]. In fact, describing the effects of mosquito-ITN contact still relies on a set of World Health Organization (WHO) recommended standard bioassays with protocols that record immediate knock down or mortality after $24-48 \mathrm{~h}$, using non-blood fed adult female mosquitoes, exposed to the active ingredient under highly artificial and simplified conditions. Details of how mosquitoes interact with the active ingredients at a net's surface have never been satisfactorily described and much remains unknown, e.g. what is the minimum duration of ITN contact necessary to deliver an effective dosage; do [some] nets have repellent properties that can prevent that threshold being reached; are there consequences of sub-threshold exposure that can affect vectorial capacity; how do all of these properties change as the net ages? Many of these knowledge gaps have been revisited since the DDT era [12-14], but satisfactory assays have yet to be developed. With the rising threat of pyrethroid resistance in Africa, recognition of the central role mosquito behaviour plays in determining the success or failure of ITN use has increased $[9,15]$.

Fundamental questions include clarification of the extent to which ITNs can or cannot repel host seeking mosquitoes. Laboratory studies have produced conflicting results, reporting that close to the ITN surface, repellency does [16-18] or does not [19, 20] occur. Clearly the net material, the insecticide used, the method of loading the net with active ingredient(s) and the age of the net are all important. Other variables may also influence these experiments: there is evidence that ITN irritancy and toxicity are reduced after bloodfeeding $[20,21]$ and that sub-lethal exposure can affect responses to the host or ITN for up to $48 \mathrm{~h}$ after exposure [22]. Resistant mosquitoes have been reported to exhibit reduced, or total loss of, irritability/repellency in response to pyrethroids [16, 17, 23-25].

Successful development of novel ITNs and other tools will need a thorough understanding of the effects of insecticide treatments on these behaviours, and of how insecticide resistance status affects mosquito-net interactions. Appropriate bioassays that are based on natural behaviour will speed up the discovery process, reducing the time taken from product concept to wide-scale deployment. Previously, an infra-red tracking system was used to describe in detail the entomological mode of action of a standard pyrethroid-treated bed net [26]. That system provides considerable insight into behaviour during host-seeking at the entire human-baited ITN but cannot capture details of behaviour during the late stages of host location, as the mosquito arrives and lands on the bed net. This report describes the 'Baited box test', a benchtop bioassay system for characterizing the final sequence of behavioural events during landing and blood feeding on a human subject through insecticidal netting.

\section{Methods}

\section{Baited box test apparatus and video}

The test arena comprises a $10 \times 10 \times 10 \mathrm{~cm}$ clear plastic-walled test chamber with a $26 \mathrm{~mm}$ diameter port, through which a single mosquito is introduced (Fig. 1). On later designs, an entry tube was added to improve control of the mosquito's release (Fig. 1b, c). The test netting is secured at a second $26 \mathrm{~mm}$ aperture on the opposite side, behind which the operator's hand, forearm or thumb can be placed, to act as an attractants and blood source. Initial concern that behavioural effects of any vapour emitted by an entire side of the chamber $(10 \times 10 \mathrm{~cm})$ would be amplified by a build-up of volatiles in the relatively small volume of the box, led to the use of this smaller test aperture. The $26 \mathrm{~mm}$ aperture is determined by the video camera field of view: fitted with a $60 \mathrm{~mm}$ lens, the camera captures the test net surface 

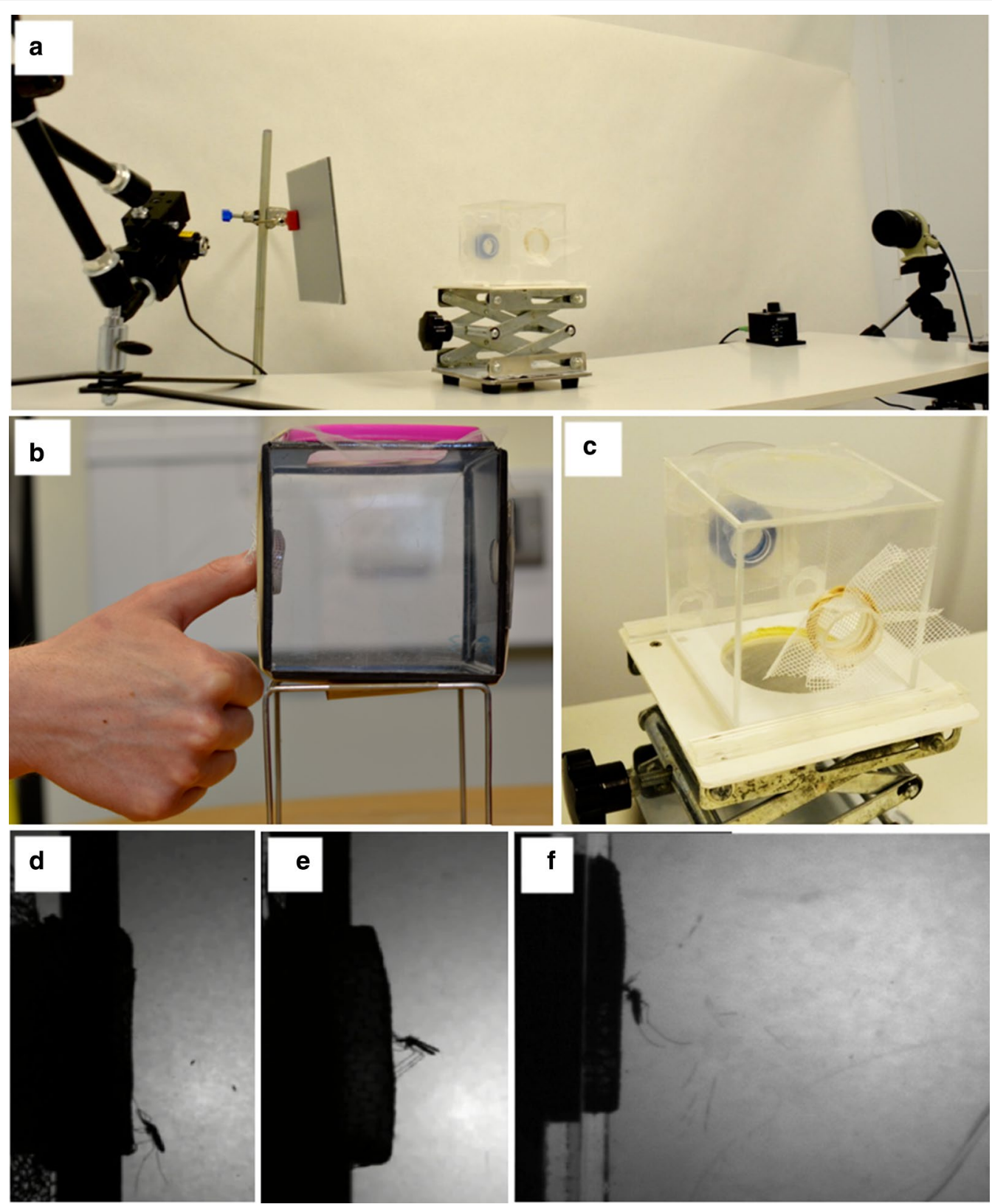

Fig. 1 Baited box test apparatus and example images. a The complete bioassay and video system with (left to right): LED (not visible inside clamp); diffuser; test chamber on adjustable table; camera and Nikon lens. Test chamber $\mathbf{b}$ without entry port (early version) and, $\mathbf{c}$ with entry port (blue ring). Sample still images from test videos (60 mm lens), showing: $\mathbf{d}$ resting post-landing, e probing, and $\mathbf{f}$ blood feeding pre-defaecation

(Fig. 1d-f) while a $50 \mathrm{~mm}$ lens captures the entire box interior. With the $60 \mathrm{~mm}$ lens, all activity at the test net surface is captured in sufficient detail to observe the defined behavioural events (Fig. 1d-f). In tests reported here, the operator's thumb was placed against the $26 \mathrm{~mm}$ test net aperture. All assays were performed in the dark.

The arena is illuminated by an infra-red light-emitting diode (850 nm, M850L2: Thorlabs, UK), positioned approximately $60 \mathrm{~cm}$ from the test chamber centre behind a diffuser placed $15-40 \mathrm{~cm}$ from the test chamber (Fig. 1a).

Mosquito behavioural responses to test netting are captured using a Dalsa Falcon 1.4Mp 100HG Camlink (Stemmer-imaging.com) camera fitted with a Nikon AF Micro-Nikkor $60 \mathrm{~mm} \mathrm{F2.8D} \mathrm{lens,} \mathrm{set} \mathrm{at} \mathrm{f} \# 11$ and positioned $30-60 \mathrm{~cm}$ from the test chamber centre (Fig. 1d). 
Images are recorded at 30 frames per second (fps) using commercial digital video recording software (either STEMMER CamExpert (CMV Movie Interactive 2) or StreamPix v.5, Norpix, Canada). Data are stored on external hard drives (e.g. Seagate 4 TB Backup plus, Amazon, UK). Video recordings are processed manually in realtime playback, with slow motion analysis as necessary.

\section{Mosquito behaviours measured}

Defining the behaviours of interest for this study was directed by the need to explore events likely to be influenced or altered by insecticide residues on bed nets, within the confines of the tracking system's capacity to record detail. Mosquito behaviours that were considered detectable and distinguishable by multiple observers during approach, landing and blood feeding were codified using an ethogram (Table 1). After reviewing the recorded videos, these nine events were combined for analyses into biologically relevant 'Activities' as shown in Table 1:

1. Response Lag Time-delay between test start and mosquito's first entry into the field of view;
2. Time to first net contact;

3. Time until feeding-time from first net contact until probing stops;

4. Readiness to land-time between first contact with the net and cessation of flight;

5. Duration of blood meal-time from proboscis insertion into skin until withdrawal

6. Resting post feed-duration of net contact post blood meal

7. Total net contact-total accumulated net contact (coloured bars with black borders on schematic).

\section{Study design}

In these studies, the behavioural responses of $A n$. gambiae s.l. female mosquitoes to treated and untreated netting were compared using three operators (AG, MA and $\mathrm{AH})$, who also acted as hosts and hence were assumed to differ in their inherent attractiveness to mosquitoes and in their ability to manipulate them safely during transfer before and after bioassays. There were additional slight but notable differences between the three studies.

Table 1 Ethogram of the behavioural events distinguishable during feeding on human bait through insecticide-treated netting

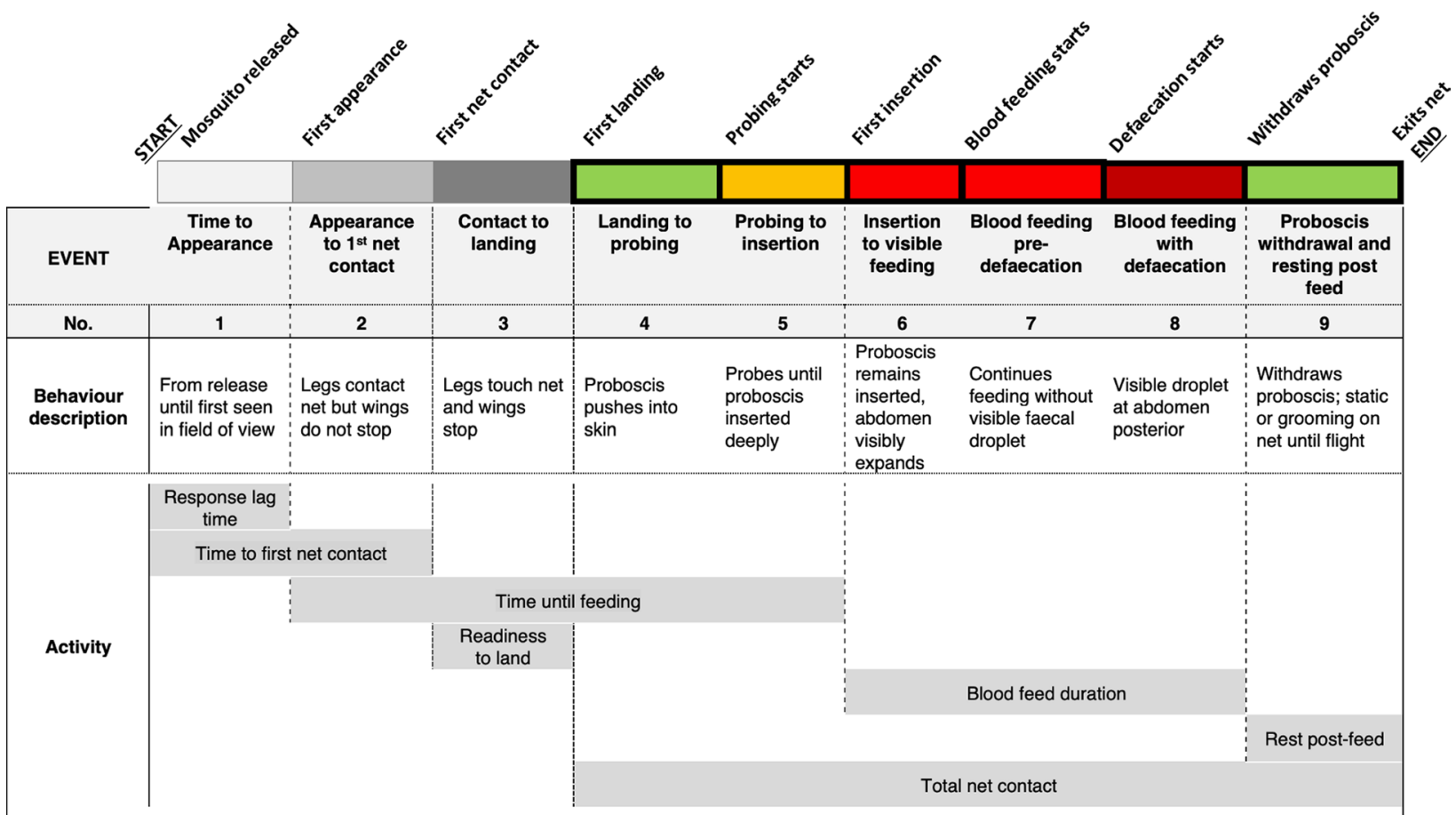

The table shows the start and endpoint of each event, and how they were grouped for each 'Activity'. Note that although events are presented in a sequence typifying an uninterrupted blood meal, individual mosquitoes could exit at any point and return to an earlier behaviour to resume the sequence or terminate. $5^{*}$ : events 4 and 5 were combined in Study 2. The colours in the horizontal bar correspond with those in Figs. 2 and 3: grey sections with no border show activity prior to first net contact; coloured sections with black borders represent behaviours involving net contact. The labels are also shown as subtitles marking the event boundaries in the accompanying video 
(a) Study 1: operator AG characterized blood-feeding behaviour of the insecticide-susceptible (IS) Kisumu strain at untreated net and one type of ITN.

(b) Study 2: MA characterized blood-feeding behaviour of the insecticide-susceptible (IS) Kisumu strain at three different bed net interfaces: two ITNs and untreated control.

(c) Study $3 \mathrm{AH}$ characterized blood-feeding behaviour of the Kisumu strain (IS) and the pyrethroid-resistant (IR) Tiassalé strain at untreated netting and one type of ITN.

In Studies 1 and 2 knock down at 60 min and mortality at $24 \mathrm{~h}$ was recorded; only $24 \mathrm{~h}$ mortality was recorded in Study 3.

\section{Mosquitoes}

Unfed female adults (aged 3-5 days post-eclosion) of either the IS Kisumu or IR Tiassale strains of An. gambiae s.l. were used in all experiments. The Kisumu colony of An. gambiae sensu stricto (s.s.), originating from Kenya, was colonized in 1953 [27]. It has been maintained at the Liverpool School of Tropical Medicine (LSTM) since 1975. The Tiassalé strain was colonized from Southern Côte d'Ivoire in 2013 and maintained at LSTM under six-monthly selection pressure with deltamethrin. This strain, which contains both An. gambiae and Anopheles coluzzii, is resistant to pyrethroids and DDT [28]. It has a high frequency of 1014F $k d r$ and ace-1 mutations and expresses elevated levels of key P450s known to metabolize pyrethroids.

Mosquitoes were starved of sugared water for at least $5 \mathrm{~h}$ prior to testing and were transferred to the experimental room at least $1 \mathrm{~h}$ prior to experiments. Lighting was dimmed and assays were performed after the first hour of the scotophase. Inactive mosquitoes that were not seen in the chamber within 5 min ( 3 min in Study 1) or active mosquitoes that had not begun probing within 10 min were discarded as non-responders.

Bioassays were run until 25 mosquitoes per treatment group had responded in Studies 1 and 2, and 20 per treatment group in Study 3. All experiments were performed in a climate-controlled insectary $\left(27 \pm 2{ }^{\circ} \mathrm{C}, 80 \pm 8 \% \mathrm{RH}\right)$ at the Liverpool School of Tropical Medicine, UK.

\section{Insecticidal netting}

Netting from two commercially available ITN brands readily available and used widely across Africa were tested.

1. PermaNet ${ }^{\circledR} 2.0$ (deltamethrin $55 \mathrm{mg} / \mathrm{m}^{2} ; 75$ denier polyester; Vestergaard, Lausanne, Switzerland), hereafter PermaNet.
2. Olyset ${ }^{\circledR}$ Net (permethrin $20 \mathrm{~g} / \mathrm{kg} \pm 3 \mathrm{~g} / \mathrm{kg} ;>150$ denier polyethylene; Sumitomo Chemical Co. Ltd., Tokyo, Japan), hereafter referred to as Olyset.

Untreated control nets were cut from polyester netting with mesh size similar to PermaNet, obtained locally in the UK and confirmed as non-insecticidal by WHO cone tests. All new ITNs were removed from packaging and hung indoors for at least 1 week before testing, to minimize any confounding risk caused by volatile contaminant odours deriving from the manufacturing or packaging processes.

\section{Data analysis}

The Fisher's exact test and Baptista-Pike method (for odds ratio) was used to compare the mosquito response rates. Behavioural events were analysed separately and in combination; comparisons between event durations were performed using ANOVA (Tukey's multiple comparisons test). In Study 1, the number of replicates was too low to analyse by ANOVA, in these cases, a non-parametric unpaired T-Test (Mann-Whitney) was used. All above analyses were carried out using GraphPad Prism v8.1.2. (GraphPad Software Inc, CA, USA). Stacked bar charts of coded behavioural events were created using GraphPad Prism v7.03.

\section{Ethical considerations}

The Liverpool School of Tropical Medicine Research Ethics Committee approved the study ('Behaviour of African malaria vectors': Permit number 12.13, issued 24th May 2012).

\section{Results}

\section{Mosquito response rates and test duration}

A total of 328 individual mosquitoes were tested of which 175 (53\%) responded (Table 2). The total numbers of mosquitoes exposed were dictated by the propensity of mosquitoes to enter the video testing arena and successfully blood feed. Conditions and endpoints were slightly different in each trial but generally $30 \mathrm{~min}$ was required to complete one bioassay, including time for setting up and post-test cleaning. The most rapidly responding mosquitoes exited the entrance tube, completed feeding and rested within $20 \mathrm{~min}$ or less. The low response rate in Study 1 prevented the target of 25 mosquitoes per treatment group being reached in the available time. Response rates were significantly lower in Study 1/operator 1 compared with Study 2/operator 2 (Odds Ratio $(O R)=0.112$, 95\% CI $=0.04-0.32, \quad n=81, \quad P=<0.0001)$ and Study 3/operator $3(\mathrm{OR}=0.09,95 \% \mathrm{CI}=0.03-0.27 n=79$, $P=<0.0001)$. Response rates for studies 2 and 3 did not differ $(\mathrm{OR}=1.3,95 \% \mathrm{CI}=0.44-4.81, n=64, P=0.77)$. 
Table 2 Mosquito response rates in three studies with three different operators/hosts

\begin{tabular}{|c|c|c|c|c|}
\hline \multirow[b]{3}{*}{ Study } & \multicolumn{4}{|c|}{ Response rate (\%) } \\
\hline & \multicolumn{4}{|c|}{ No mosquitoes responding/no. tested } \\
\hline & Study 1 & Study 2 & Study 3 & \\
\hline Operator & AG & MA & $\mathrm{AH}$ & \\
\hline Mosquito strain & Kisumu & Kisumu & Kisumu & Tiassalé \\
\hline \multicolumn{5}{|l|}{ Treatment } \\
\hline Untreated & $27 \%(13 / 48)$ & $76 \%(25 / 33)$ & $77 \%(20 / 26)$ & $67 \%(20 / 30)$ \\
\hline PermaNet 2 & $18 \%(7 / 38)$ & $58 \%(25 / 43)$ & $61 \%(20 / 33)$ & $61 \%(20 / 33)$ \\
\hline Olyset & & $57 \%(25 / 44)$ & & \\
\hline Total no. tested & 86 & 120 & 59 & 63 \\
\hline
\end{tabular}

Within each study, there were no significant differences in responses to Untreated nets and PermaNet 2.0 or Olyset ITNs: Study 1: $X^{2}(1, n=86)=0.89$, $\mathrm{p}=0.35, \mathrm{OR}=0.61,95 \% \mathrm{Cl}=0.22-1.72)$; Study 2: $(1, n=75)=2.57, \mathrm{p}=0.11$, $\mathrm{OR}=0.77,95 \% \mathrm{Cl}=0.37-1.58) ;$ Study 3 (Kisumu) $(1, n=59)=1.77, \mathrm{p}=0.18$, $\mathrm{OR}=0.79,95 \% \mathrm{Cl}=0.35-1.76)$ and Study 3 (Tiassalé) $(1, n=63)=0.25, \mathrm{p}=0.617$ $\mathrm{OR}=0.91,95 \% \mathrm{Cl}=0.41-2.01)$

Response rates to ITNs were not significantly different to untreated nets. In all tests, there was no indication that the insecticide treated net reduced a mosquito's readiness to respond to the host, prior to net contact (Study 1: $\mathrm{OR}=1.65,95 \% \mathrm{CI}=0.56-4.25, n=86, P=0.44$; Study 2 : $\mathrm{OR}=2.25,95 \% \mathrm{CI}=0.84-6.36, n=75, P=0.15$; Study 3 (Kisumu) $\mathrm{OR}=2.17,95 \% \mathrm{CI}=0.70-7.37, n=59, P=0.26$ and Study 3 (Tiassalé) OR $=1.3,95 \% \mathrm{CI}=0.49-3.57$, $n=63, P=0.80)$. Response rates of mosquitoes from a resistant strain (Tiassalé) did not differ from the susceptible strain (Kisumu) during exposure to untreated nets $(\mathrm{OR}=1.6,95 \% \mathrm{CI}=0.48-5.7, n=56, P=0.39)$ or PermaNet ITNs $(\mathrm{OR}=1,95 \% \mathrm{CI}=0.35-2.8, n=66$, $P=>0.99)$.

\section{Blood-feeding behaviour of pyrethroid susceptible Anopheles gambiae at untreated netting}

The sequence of behaviours observed between a mosquito's arrival at the bed net surface, through probing and blood feeding until its departure from the net, are presented in Fig. 2, Table 3 and in Additional file 1: supplementary video. This sequence of events was similar in all studies, but the duration of certain key events was highly variable.

Prior to blood-feeding: lag times ranged from 0 to $4.25 \mathrm{~min}$, times from appearance to first net contact

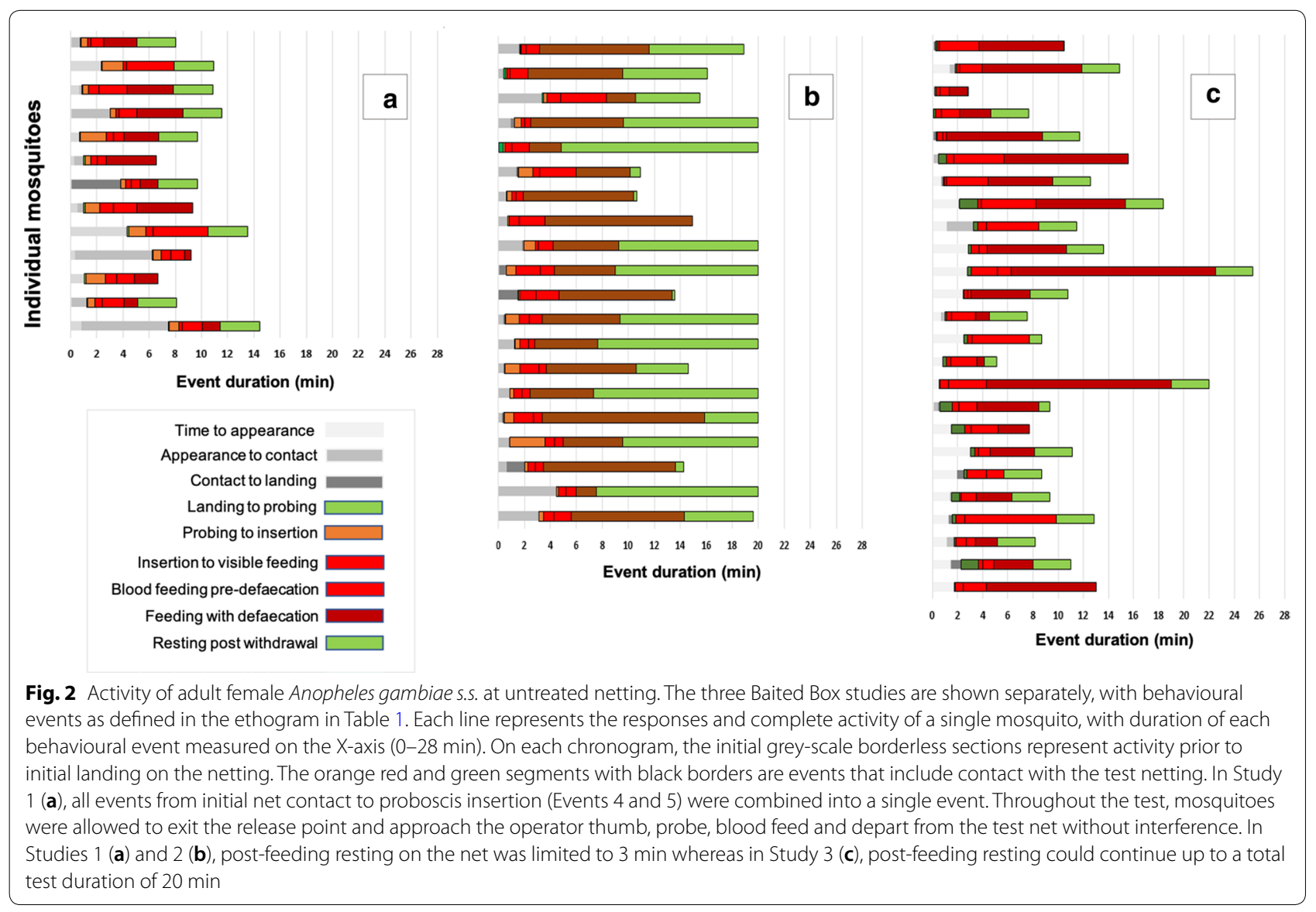


Table 3 Duration and percentage proportion of selected events for the IS Kisumu strain of Anopheles gambiae when exposed to PermaNet and Olyset in the Baited box test

\begin{tabular}{|c|c|c|c|c|c|c|}
\hline Event $^{a}$ & 1 & 3 & $2,3,4,5$ & $6,7,8$ & 4-9 & 9 \\
\hline Activity $^{a}$ & Response lag time & Readiness to land & $\begin{array}{l}\text { Appearance } \\
\text { to blood feed start }\end{array}$ & Blood feed duration & $\begin{array}{l}\text { Total net } \\
\text { contact } \\
\text { duration }\end{array}$ & Resting post feed \\
\hline
\end{tabular}

Net Mean duration (minutes), SD, range, proportion of total assay length

\begin{tabular}{|c|c|c|c|c|c|c|}
\hline \multicolumn{7}{|c|}{ Study 1} \\
\hline UT & $\begin{array}{l}0.85 \\
1.19 \\
0-4.25 \\
8 \%\end{array}$ & $\begin{array}{l}0.29 \\
1.03 \\
0-3.73 \\
3 \%\end{array}$ & $\begin{array}{l}2.71 \\
2.14 \\
1.27-8.28 \\
27 \%\end{array}$ & $\begin{array}{l}4.25 \\
1.42 \\
2.27-7.05 \\
45 \%\end{array}$ & $\begin{array}{l}7.58 \\
2.0 \\
2.97-9.9878 \%\end{array}$ & $\begin{array}{l}2.08 \\
1.44 \\
0-3 \\
20 \%\end{array}$ \\
\hline P2 & $\begin{array}{l}0.94 \\
0.79 \\
0.13-2.05 \\
14 \%\end{array}$ & $\begin{array}{l}0.01 \\
0.012 \\
0-0.3 \\
0.11 \%\end{array}$ & $\begin{array}{l}2.11 \\
0.93 \\
1.18-3.4728 \%\end{array}$ & $\begin{array}{l}2.59 \\
1.13 \\
1.57-4.58,34 \%\end{array}$ & $\begin{array}{l}5.82 \\
2.3 \\
2.4-7.95 \\
73 \%\end{array}$ & $\begin{array}{l}2.14 \\
1.46 \\
0-3 \\
24 \%\end{array}$ \\
\hline \multicolumn{7}{|c|}{ Study 2} \\
\hline UT & $\begin{array}{l}1.26 \\
0.94 \\
0.01-1.16 \\
11 \%\end{array}$ & $\begin{array}{l}0.11 \\
0.18 \\
0-0.77 \\
1 \%\end{array}$ & $\begin{array}{l}0.68 \\
0.63 \\
0.09-2.5 \\
6 \%\end{array}$ & $\begin{array}{l}7.50 \\
4.66 \\
2.48-19.4 \\
65 \%\end{array}$ & $\begin{array}{l}10.04 \\
4.80 \\
2.65-22.7 \\
87 \%\end{array}$ & $\begin{array}{l}2.16 \\
1.28 \\
0-3 \\
19 \%\end{array}$ \\
\hline P2 & $\begin{array}{l}0.99 \\
1.04 \\
0.05-2.7 \\
12 \%\end{array}$ & $\begin{array}{l}1.56 \\
2.17 \\
0.02-8.12 \\
18 \%\end{array}$ & $\begin{array}{l}2.43 \\
2.18 \\
0.2-8.25 \\
28 \%\end{array}$ & $\begin{array}{l}3.77 \\
1.64 \\
1.1-7.08 \\
44 \%\end{array}$ & $\begin{array}{l}5.38 \\
1.93 \\
1.9-9.2 \\
63 \%\end{array}$ & $\begin{array}{l}1.38 \\
1.14 \\
0-3 \\
16 \%\end{array}$ \\
\hline O & $\begin{array}{l}0.89 \\
1.10 \\
0.02-0.35 \\
10 \%\end{array}$ & $\begin{array}{l}1.69 \\
2.10 \\
0.02-8.07 \\
20 \%\end{array}$ & $\begin{array}{l}2.76 \\
2.44 \\
0.3-8.5 \\
32 \%\end{array}$ & $\begin{array}{l}4.45 \\
1.61 \\
1.7-7.5 \\
51 \%\end{array}$ & $\begin{array}{l}5.33 \\
1.98 \\
2.2-9.7 \\
61 \%\end{array}$ & $\begin{array}{l}0.57 \\
0.93 \\
0-3 \\
7 \%\end{array}$ \\
\hline \multicolumn{7}{|c|}{ Study 3} \\
\hline UT & $\begin{array}{l}1.15 \\
1.20 \\
0.65-1.75 \\
7 \%\end{array}$ & $\begin{array}{l}0.01 \\
0.02 \\
0-0.017 \\
<1.0 \%\end{array}$ & $\begin{array}{l}0.85 \\
0.68 \\
0.15-2.78 \\
5 \%\end{array}$ & $\begin{array}{l}8.47 \\
1.67 \\
7.04-9.87 \\
49 \%\end{array}$ & $\begin{array}{l}16.10 \\
3.43 \\
14.47-17.68 \\
92 \%\end{array}$ & $\begin{array}{l}7.17 \\
3.80 \\
4.67-9.32 \\
40 \%\end{array}$ \\
\hline P2 & $\begin{array}{l}1.57 \\
1.41 \\
0.91-2.23 \\
17 \%\end{array}$ & $\begin{array}{l}0.01 \\
0.02 \\
0-0.05 \\
<1.0 \%\end{array}$ & $\begin{array}{l}0.98 \\
0.78 \\
0.17-2.6 \\
11 \%\end{array}$ & $\begin{array}{l}4.72 \\
1.67 \\
3.93-5.49 \\
52 \%\end{array}$ & $\begin{array}{l}7.17 \\
3.79 \\
5.38-8.94 \\
79 \%\end{array}$ & $\begin{array}{l}1.81 \\
3.48 \\
0.17-3.44 \\
20 \%\end{array}$ \\
\hline
\end{tabular}

The proportion of recorded time spent on each event is shown as a percentage of total assay length. Untreated net data included for comparison purposes. ( ${ }^{\mathrm{a}} \mathrm{see}$ Table 2)

from 0 to $7.47 \mathrm{~min}$, and first net contact to initiation of probing $0.09-8.28 \mathrm{~min}$. The three events comprising blood feeding duration ranged from 2.27 to $19.4 \mathrm{~min}$. Post-feeding, mosquitoes remained on the net surface, either resting or grooming, for between 0 and $9.32 \mathrm{~min}$. Total net contact times were recorded at a range of between 2.65 and $22.7 \mathrm{~min}$.

There were significant differences between the three studies in some key events (Fig. 2, Table 3). Blood-feeding duration was significantly longer in Study 3 (mean $8.47 \mathrm{~min}, 95 \% \mathrm{CI}=7.05-9.88$ ) than in Studies 1 (mean $4.25 \mathrm{~min}, 95 \%$ CI $3.39-5.11, P=0.005$ ) and 2 (mean $7.5 \mathrm{~min}, 95 \% \mathrm{CI}=5.57-9.42, P=0.029)$. Time until blood feeding was significantly longer in Study 1 (mean $2.71 \mathrm{~min}, 95 \% \mathrm{CI}=1.42-3.99$ ) compared to Study 2 (mean $0.68 \mathrm{~min}, 95 \% \mathrm{CI}=0.42-0.94, \quad P=<0.0001$ ) and Study 3 (mean $0.85 \mathrm{~min}, 95 \% \mathrm{CI}=0.53-1.16$, $P=<0.0001)$.

Following untreated net exposure, knock down at $60 \mathrm{~min}$ and/or mortality at $24 \mathrm{~h}$ was $<10 \%$ in all studies.

\section{Blood-feeding behaviour of pyrethroid susceptible $A n$. gambiae at an insecticide-treated net}

The basic sequence of events was not different to an untreated net (Fig. 3; Table 3). However, the duration of blood feeding was reduced by $37-50 \%$ at ITNs, significantly shorter than on untreated netting (PermaNet: Study 1 , mean $2.59 \mathrm{~min}, 95 \% \mathrm{CI}=1.54-3.63, P=0.01$; Study 2, mean $3.77 \mathrm{~min}, 95 \% \mathrm{CI}=3.10-4.45, P=0.0001$; 


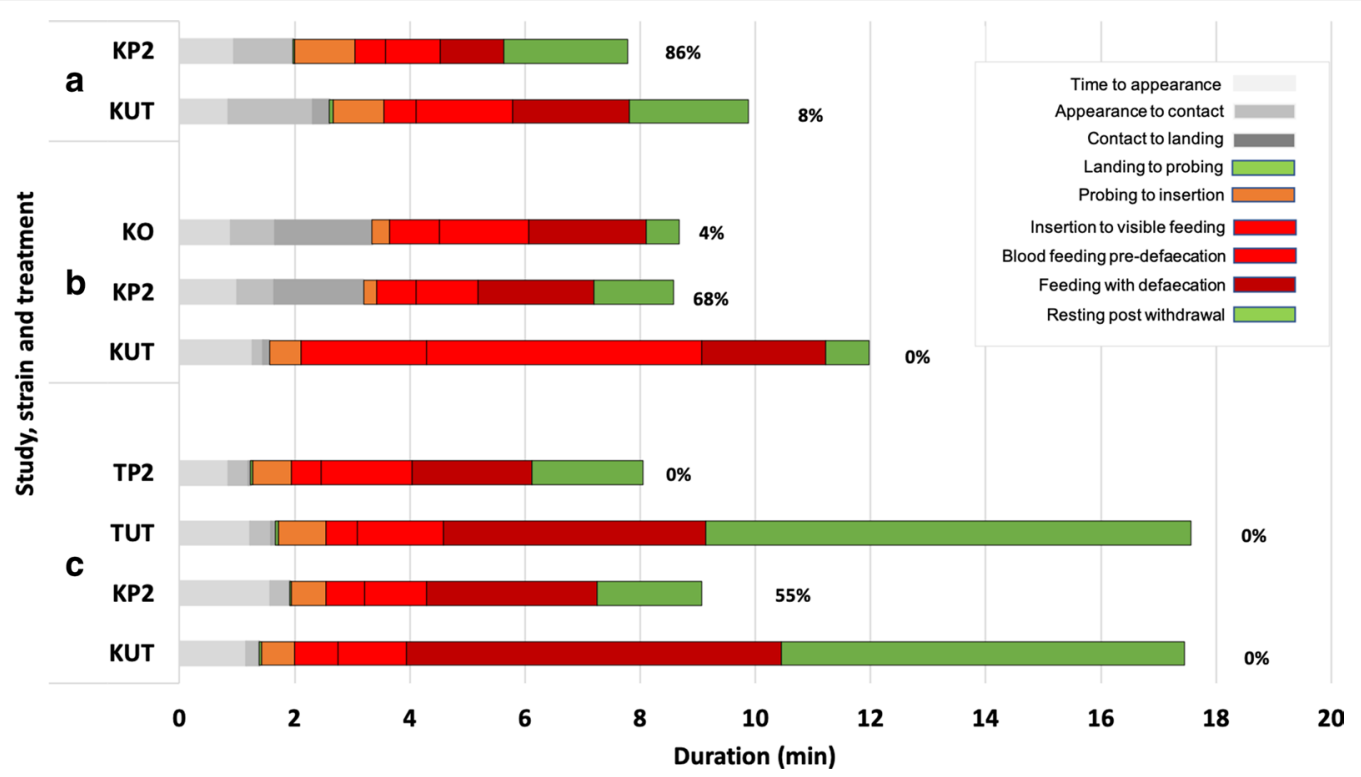

Fig. 3 Blood feeding behaviour of insecticide susceptible and insecticide resistant Anopheles gambiae at pyrethroid treated netting Stacked barcharts showing responses of pyrethroid susceptible Kisumu (K) and Tiassale (T) strains in Baited Box tests of untreated (UT), PermaNet (P2) or Olyset (O) netting in Study 1 (a), Study 2 (b) and Study 3 (c). Each stacked bar chart represents the mean durations of each coded behavioural event in each test (Study 1: $n=13$ for untreated net and 7 for PermaNet, Study 2: $n=25$ mosquitoes per group, Study 3: $n=20$ mosquitoes per group). The percentage mortality at $24 \mathrm{~h}$ post testing for each treatment group is shown at the end of each bar. In Studies 1 and 2, post-feeding resting on the net was limited to 3 min whereas in Study 3, post-feeding resting could continue up to a total test duration of 20 min

Study 3, mean $4.72 \mathrm{~min}, 95 \% \mathrm{CI}=7.05-9.89, P=<0.0001$; Olyset (Study 2 only): mean $4.45 \mathrm{~min}, 95 \% \mathrm{CI}=3.8-5.12$, $P=0.0017$; PermaNet vs Olyset $(P=0.699)$.

Total net contact duration was also reduced on ITNs compared with untreated netting in Study 2 (PermaNet, mean $5.38 \mathrm{~min}, 95 \% \mathrm{CI}=4.6-6.17, P=<0.0001$ and Olyset, mean $5.33 \mathrm{~min}, 95 \% \mathrm{CI}=4.52-6.2, P=<0.0001$ versus untreated net, mean $10.04 \mathrm{~min}, 95 \% \mathrm{CI}=8.05-$ 12.02) and Study 3 (PermaNet, mean $7.17 \mathrm{~min}, 95 \%$ $\mathrm{CI}=5.4-8.9, P=<0.0001$ versus untreated net, mean $16.10 \mathrm{~min}, 95 \% \mathrm{CI}=14.5-17.7$ ).

Time to first net contact (events 1 and 2) is the period when volatile chemicals from the net would exert an influence on behaviour (i.e. true repellency rather than excito-repellency). With no significant difference in the duration of this activity between untreated nets and PermaNets $(P>0.3)$ or Olysets $(P=0.21)$ or between both ITNs $(P=0.93)$, these results indicate that neither ITN has spatial repellent properties.

However, after initial contact, there was a significant increase in the time from appearance to commencement of blood feeding (willingness to feed) with Olyset (mean $2.76 \mathrm{~min}, 95 \% \mathrm{CI}=1.7-3.8, P=0.0009$ ) and PermaNet (mean $2.4 \mathrm{~min}, 95 \% \mathrm{CI}=1.52-3.33, P=0.0058$ ) compared to untreated netting (mean $0.68 \mathrm{~min}, 95 \%$ $\mathrm{CI}=0.42-0.95)$. There was also a difference in the time from first net contact to landing (readiness to land) on ITNs in Study 2 (PermaNet, mean $1.56 \mathrm{~min}, 95 \%$ $\mathrm{CI}=0.67-2.5, P=0.012$; Olyset, mean $1.69 \mathrm{~min},(95 \%$ $\mathrm{CI}=0.84-2.56, P=0.006)$ compared to untreated netting (mean $0.11 \mathrm{~min}, 95 \% \mathrm{CI}=0.04-0.19$ ).

In Study 1 (PermaNet), both knockdown and $24 \mathrm{~h}$ mortality were 86\%; in Study 2, knockdown at $60 \mathrm{~min}$ was $96 \%(24 / 25)$ and $24 \%(6 / 25)$, and mortality at $24 \mathrm{~h}$ was 68\% (17/25) and 4\% (1/25) for PermaNet and Olyset, respectively. In Study 3 (PermaNet), at $24 \mathrm{~h}$ post-exposure, mortality was $55 \%$.

\section{Blood feeding behaviour of pyrethroid resistant $A n$. gambiae at an insecticide-treated net}

The behaviour of pyrethroid resistant mosquitoes did not differ from that of susceptible strains and the effects of ITNs on the behaviour of both strains were similar (Fig. 3). When resistant mosquitoes fed through PermaNet ITNs, the duration of blood feeding (mean $4.20 \mathrm{~min}, 95 \% \mathrm{CI}=3.42-5.0$ ), post feed resting (tolerance of irritation (mean $1.93 \mathrm{~min}, 95 \% \mathrm{CI}=0.44-3.41$ ) and total accumulated time in contact with the net (mean $6.87 \mathrm{~min}, 95 \% \mathrm{CI}=4.96-8.77)$ were significantly lower $(P=<0.001)$ than at untreated controls (blood feeding: mean $6.60 \mathrm{~min}, 95 \% \mathrm{CI}=5.28-7.91$; resting: mean $8.43 \mathrm{~min}, 95 \% \mathrm{CI}=6.0710 .78$ and total net contact: mean 
$16.10 \mathrm{~min}, 95 \% \mathrm{CI}=14.49-17.7)$. Mortality of the IR strain was zero at $24 \mathrm{~h}$ post exposure.

\section{Discussion}

This study describes, at an exceptional level of detail, the behaviour of host-seeking An. gambiae during the critical final stages of arrival, landing and blood-feeding through untreated and insecticide-treated bed nets. The results reveal a highly-conserved behaviour. Human attractiveness to mosquitoes varies between individuals and could account for the differences in response rates and at least some of the variation in duration of mosquito behaviours between the three operators. However, regardless of operator, net treatment or mosquito strain, the behavioural responses recorded with this system were remarkably consistent across all tests.

At untreated nets, behaviour of all mosquitoes, whether susceptible or resistant to pyrethroids, followed an ordered sequence of events (Table 1), though there was considerable variation in the duration of each stage in the sequence. At insecticide-treated nets (PermaNet and Olyset ITNs), the sequence of events was the same as at untreated nets, but the durations of blood-feeding and resting post-feeding and the total time accrued in contact with the net, were significantly reduced. The time from appearance to commencement of blood feeding was slightly higher than at untreated nets.

The Baited Box Test partners the room-scale flight tracking system $[26,29]$ to provide details of the closing stages of mosquito-net interaction that are not captured in the larger-scale assay. Applied to the PermaNet ITN, findings from this and the room-scale test [26] are compatible, defining it as an ITN with negligible repellency. Even at very close range, the mosquito's behaviour prior to contact is virtually indistinguishable to that seen at untreated nets. Post-contact, the PermaNet's irritant properties reduce net contact, before, during and after blood-feeding. Based on the limited number of tests performed to date, the responses to an Olyset are not dissimilar, but tracking flight data and tests with additional mosquito strains are needed before drawing a conclusion. These results also serve to illustrate the importance of maintaining a balance between the toxic/lethal and repellent/irritant properties of an ITN to ensure a lethal dose is delivered before a mosquito leaves the net.

Previous studies [30] and [31] have reported reductions in feeding rates of resistant Anopheles spp. on pyrethroid-treated nets, with Glunt et al. [30] reporting up to $60 \%$ reduction when mosquitoes were offered a blood meal immediately after ITN exposure. Hauser et al. [20] reported that pyrethroid susceptible An. gambiae mosquitoes commenced blood feeding later (53.5 s vs. $35 \mathrm{~s}$ after start of test) and spent less time feeding (40 s vs. 175 s) through an Olyset Plus insecticidal net than through untreated netting, respectively. The baited box setup permits measurement in finer detail than was possible in these studies, e.g. one can distinguish between behaviours prior to net contact (true volatile repellency) and those that occurred after net contact (contact irritation/excito-repellency), a detail that eluded Hauser et al. [20] who could not conclude whether or not their Olyset Plus exhibited spatial repellency.

Experimental results showed that an average of 55\% of blood-fed susceptible individuals survived $24 \mathrm{~h}$ after blood feeding through a PermaNet. Almost certainly the result of reduced net contact, this phenomenon was first reported over 30 years ago by Hossain and Curtis [32] who reported $40 \%$ survival in An. gambiae after feeding through permethrin-dipped nets. Others found evidence for the blood meal's protective effect in resistant strains of An. funestus and Anopheles arabiensis [21, 33, 34] and in a wild population in Burkina Faso [35]. Recently, Hauser et al. reported $85 \%$ survival rates in susceptible An. gambiae, $24 \mathrm{~h}$ after exposure [20].

The Baited box test can contribute to the search for next-generation insecticidal netting in the laboratory as a screening assay for new insecticides, to evaluate performance against, or to monitor resistance in, a vector population and as a bioassay to measure durability of aged nets. The current testing pipeline for new insecticidal vector control products typically follows the WHO Pesticide Evaluation Scheme (WHOPES), which involves phase I laboratory testing, phase II small scale field trials and phase III large scale field trials. However, the assays currently used in phase I evaluations, the WHO cone, tube and tunnel tests, are poorly linked to most products' actual modes of action in field settings, as they record knockdown and mortality after brief, but forced, exposure providing no data on duration of contact with the insecticide, a key element of any net's power to deliver a lethal dose. In contrast, the Baited-box test measures behaviour of free-flying mosquitoes attempting to feed on a human host behind a bed net, thereby quantifying behaviour in a far more field-relevant setup than the existing tests.

\section{Conclusion}

The Baited Box test was developed to accelerate the development and delivery of effective vector control products to communities at risk of malaria, by providing the evidence required to select the most appropriate ITN to target that vector population and for routine use thereafter in monitoring it for insecticide resistance. In today's 'post-pyrethroid era, assessment of efficacy in the field must capture far more than immediate knockdown and mortality effects, as was done for pyrethroid-only nets. The results presented 
in this report demonstrate the Baited-box's potential as a screening assay for that purpose. The outputs from studies where the Baited box was used to evaluate impacts of nextgeneration ITNs in the field and laboratory will be available to report in the immediate future.

\section{Supplementary information}

Supplementary information accompanies this paper at https://doi. org/10.1186/s12936-020-03213-9.

Additional file 1. Baited Box Assay video. Complete video recording of a Baited box assay. A single female Anopheles gambiae (pyrethroid resistant Tiassale strain) feeding on a human thumb through insecticide treated netting (PermaNet 2.0). The definitions of each behaviour event, activity and the colour scheme of the subtitles in the video correspond with those in Table 1. The video is the complete unedited recording and is reproduced at natural speed. The key timepoints that mark the divisions between each event are labelled in the video as subtitles, in the following sequence: (1) START/Mosquito released 00.00 (2) First appearance in field of view 00.26 (3) First net contact 01.11 (4) First landing on net 01.11 (5) Probing starts 01.12 (6) First insertion of proboscis 01.41 (7) Blood feeding starts 01.57 (8) Defaecation starts 03.45 (9) Withdraws proboscis 05.18 (10) Exits the net 05.23/END.

\section{Acknowledgements}

We thank N. Angarita-Jaimes for contributing to the video system's design and assembly, J Parker for guidance in its operation and G Murray, N. Lissenden and J Jones for ad hoc support. We thank $H$. Ranson for numerous discussions and long-term support.

\section{Authors' contributions}

PJM conceived the test and PJM and MA constructed the first test chambers; PJM and MA designed the experiments; DT designed the illumination and camera system; MA, AG, AH and GMF carried out the experiments and, with $\mathrm{AM}$, analysed the data; $\mathrm{AH}, \mathrm{GMF}$ and PJM wrote the manuscript and all authors contributed to the final draft. All authors read and approved the final manuscript.

\section{Funding}

This work was funded by Bill \& Melinda Gates Foundation (BMGF OPP1 159078), and The Wellcome Trust (Malaria in Insecticide Resistant Africa (MIRA); 200222/Z/15/Z).

\section{Availability of data and materials}

The datasets used in this study are available from the corresponding author on reasonable request.

\section{Ethics Approval and consent to participate}

The study ('Behaviour of African malaria vectors') was approved by The Liverpool School of Tropical Medicine Research Ethics Committee on $24^{\text {th }}$ May 2012 (Permit number 12.13).

\section{Consent for publication}

All authors have approved the submitted manuscript.

\section{Competing interests}

The authors declare that they have no competing interests.

\section{Author details}

${ }^{1}$ Department of Vector Biology, Liverpool School of Tropical Medicine, Pembroke Place, Liverpool L3 5QA, UK. ${ }^{2}$ Optical Engineering Group, School of Engineering, University of Warwick, Coventry CV4 7AL, UK.

Received: 8 February 2020 Accepted: 28 March 2020 Published online: 07 April 2020

\section{References}

1. Bhatt S, Weiss DJ, Cameron E, Bisanzio D, Mappin B, Dalrymple U, et al. The effect of malaria control on Plasmodium falciparum in Africa between 2000 and 2015. Nature. 2015;526:207-11.

2. WHO. Global technical strategy for malaria 2016-2030. Geneva: World Health Organization; 2015.

3. Churcher TS, Lissenden N, Griffin JT, Worrall E, Ranson H. The impact of pyrethroid resistance on the efficacy and effectiveness of bednets for malaria control in Africa. Elife. 2016;5:e16090.

4. Protopopoff N, Mosha JF, Lukole E, Charlwood JD, Wright A, Mwalimu $C D$, et al. Effectiveness of a long-lasting piperonyl butoxide-treated insecticidal net and indoor residual spray interventions, separately and together, against malaria transmitted by pyrethroid-resistant mosquitoes: a cluster, randomised controlled, two-by-two factorial design trial. Lancet. 2018;391:1577-88.

5. Killeen GF, Ranson H. Insecticide-resistant malaria vectors must be tackled. Lancet. 2018;391:1551-2.

6. Tchakounte A, Tchouakui M, Mu-Chun C, Tchapga W, Kopia E, Soh PT, et al. Exposure to the insecticide-treated bednet PermaNet 2.0 reduces the longevity of the wild African malaria vector Anopheles funestus but GSTe2-resistant mosquitoes live longer. PLoS ONE. 2019;14:e0213949.

7. Pryce J, Richardson M, Lengeler C. Insecticide-treated nets for preventing malaria. Cochrane Database Syst Rev. 2018;11:CD000363.

8. Hemingway J. The way forward for vector control. Science. 2017;358:998-9.

9. Gatton ML, Chitnis N, Churcher T, Donnelly MJ, Ghani AC, Godfray HC, et al. The importance of mosquito behavioural adaptations to malaria control in Africa. Evolution. 2013;67:1218-30.

10. Russell TL, Beebe NW, Cooper RD, Lobo NF, Burkot TR. Successful malaria elimination strategies require interventions that target changing vector behaviours. Malar J. 2013;12:56.

11. Sokhna C, Ndiath MO, Rogier C. The changes in mosquito vector behaviour and the emerging resistance to insecticides will challenge the decline of malaria. Clin Microbiol Infect. 2013;19:902-7.

12. Kennedy JS. The excitant and repellent effects on mosquitos of sub-lethal contacts with DDT. Bull Ent Res. 1947;37:593-607.

13. Muirhead-Thomson RC. The significance of irritability, behaviouristic avoidance and allied phenomena in malaria eradication. Bull World Health Organ. 1960;22:721-34.

14. Roberts $D R$, Andre $R G$. Insecticide resistance issues in vector-borne disease control. Am J Trop Med Hyg. 1994;50:21-34.

15. Sherrard-Smith E, Skarp JE, Beale AD, Fornadel C, Norris LC, Moore SJ. Mosquito feeding behavior and how it influences residual malaria transmission across Africa. Proc Natl Acad Sci USA. 2019;116:15086-95.

16. Siegert PY, Walker E, Miller JR. Differential behavioral responses of Anopheles gambiae (Diptera: Culicidae) modulate mortality caused by pyrethroid-treated bednets. J Econ Entomol. 2009;102:2061-71.

17. Kawada H, Ohashi K, Dida GO, Sonye G, Njenga SM, Mwandawiro C, et al. Insecticidal and repellent activities of pyrethroids to the three major pyrethroid-resistant malaria vectors in western Kenya. Parasit Vectors. 2014;7:208.

18. Parker JE, Jaimes NC, Gleave K, Mashauri F, Abe M, Martine J, et al. Hostseeking activity of a Tanzanian population of Anopheles arabiensis at an insecticide treated bed net. Malar J. 2017;16:270.

19. Spitzen J, Ponzio C, Koenraadt CJ, Jamet HV, Takken W. Absence of close-range excitorepellent effects in malaria mosquitoes exposed to deltamethrin-treated bed nets. Am J Trop Med Hyg. 2014;90:1124-32.

20. Hauser G, Thiévent K, Koella JC. The ability of Anopheles gambiae mosquitoes to bite through a permethrin-treated net and the consequences for their fitness. Sci Rep. 2019;9:8141.

21. Oliver SV, Brooke BD. The effect of multiple blood-feeding on the longevity and insecticide resistant phenotype in the major malaria vector Anopheles arabiensis (Diptera: Culicidae). Parasit Vectors. 2014;7:390.

22. Thiévent $\mathrm{K}$, Hauser G, Elaian $\mathrm{O}$, Koella JC. The interaction between permethrin exposure and malaria infection affects the host-seeking behaviour of mosquitoes. Malar J. 2019;18:79.

23. Rowland M. Flight activity of insecticide resistant and susceptible Anopheles stephensi mosquitoes in actograph chambers lined with malathion, үHCH or dieldrin. Med Vet Entomol. 1990;4:397-404. 
24. Hodjati MH, Curtis CF. Dosage differential effects of permethrin impregnated into bednets on pyrethroid resistant and susceptible genotypes of the mosquito Anopheles stephensi. Med Vet Entomol. 1997;11:368-72.

25. Chandre F, Darriet F, Duchon S, Finot L, Manguin S, Carnevale P, et al. Modifications of pyrethroid effects associated with kdr mutation in Anopheles gambiae. Med Vet Entomol. 2000;14:81-8.

26. Parker JE, Angarita-Jaimes N, Abe M, Towers CE, Towers D, McCall PJ. Infrared video tracking of Anopheles gambiae at insecticide-treated bed nets reveals rapid decisive impact after brief localised net contact. Sci Rep. 2015;5:13392.

27. Shute GT. A method of maintaining colonies of East African strains of Anopheles gambiae. Ann Trop Med Parasitol. 1956;50:92-4.

28. Williams J, Flood L, Praulins G, Ingham VA, Morgan J, Lees RS, et al. Characterisation of Anopheles strains used for laboratory screening of new vector control products. Parasit Vectors. 2019;12:522.

29. Angarita-Jaimes NC, Parker JE, Abe M, Mashauri F, Martine J, Towers CE, et al. A novel video-tracking system to quantify the behaviour of nocturnal mosquitoes attacking human hosts in the field. J R Soc Interface. 2016;13:20150974.

30. Glunt KD, Coetzee M, Huijben S, Koffi AA, Lynch PA, N'Guessan R, et al. Empirical and theoretical investigation into the potential impacts of insecticide resistance on the effectiveness of insecticide-treated bed nets. Evol Appl. 2018;11:431-41.
31. Mulatier M, Pennetier C, Porciani A, Chandre F, Dormont L, Cohuet A. Prior contact with permethrin decreases its irritancy at the following exposure among a pyrethroid-resistant malaria vector Anopheles gambiae. Sci Rep. 2019;9:8177.

32. Hossain Ml, Curtis CF. Permethrin-impregnated bednets: behavioural and killing effects on mosquitoes. Med Vet Entomol. 1989;3:367-76.

33. Spillings BL, Coetzee M, Koekemoer LL, Brooke BD. The effect of a single blood meal on the phenotypic expression of insecticide resistance in the major malaria vector Anopheles funestus. Malar J. 2008;7:226.

34. Oliver SV, Brooke BD. The role of oxidative stress in the longevity and insecticide resistance phenotype of the major malaria vectors Anopheles arabiensis and Anopheles funestus. PLOS ONE. 2016;11:e0151049.

35. Hughes A, Lissenden N, Viana M, Toé KH, Ranson H. Anopheles gambiae populations from Burkina Faso show minimal delayed mortality after exposure to insecticide-treated nets. Parasit Vectors. 2020;13:17.

\section{Publisher's Note}

Springer Nature remains neutral with regard to jurisdictional claims in published maps and institutional affiliations.
Ready to submit your research? Choose BMC and benefit from:

- fast, convenient online submission

- thorough peer review by experienced researchers in your field

- rapid publication on acceptance

- support for research data, including large and complex data types

- gold Open Access which fosters wider collaboration and increased citations

- maximum visibility for your research: over $100 \mathrm{M}$ website views per year

At BMC, research is always in progress.

Learn more biomedcentral.com/submissions 